\title{
Evaluation of two models of saddles on the back of Arabian horses through thermography
}

\author{
Avaliação de dois modelos de selas sobre o dorso de cavalos Árabes com o \\ emprego da termografia
}

\author{
Renata Farinelli de Siqueira ${ }^{1}$ (D); Beatriz Moreira Andrioli²; Marina Juliani Baumhak ${ }^{3}$ \\ ${ }^{1}$ Universidade Cruzeiro do Sul, Departamento de Medicina Veterinária, São Paulo - SP, Brazil \\ ${ }^{2}$ Universidade de Guarulhos, Faculdade de Medicina Veterinária, São Paulo - SP, Brazil \\ ${ }^{3}$ Universidade de São Paulo, Faculdade de Medicina Veterinária e Zootecnia, São Paulo - SP, Brazil
}

\begin{abstract}
Dorsopathies are common causes of decreased performance in athletic horses of various modalities, and inadequate or poorly adjusted saddles can lead to the onset of injuries and low back pain. The present study, searching to find the most appropriate saddle, evaluated the pressure determined from the panels of two saddle models most commonly used in endurance Arab horse on the thoracolumbar region. For the study, six Arabian geldings were used, weighing $390 \pm 4.2$ and $2.1 \pm$ age 8 years, conditioned to endurance races, and two saddle models, English and Western. The horses were submitted to the work riding on a sandy lane by the same experienced rider who weighed $76 \mathrm{~kg}$. Thermography was performed before and after each exercise session. The obtained data were analyzed through Student's paired t-test at $5 \%$ of significance. After exercise, there was a mean temperature difference between the contact areas of the right and left of the sweepers of two saddles compared, with the English saddle showing higher temperatures. Therefore, the Western saddle model, which has wider panels, despite not being a preferred model of endure riders, has proved to be more suitable for Arabian horse work.
\end{abstract}

Keywords: Saddle fitting. Endurance horse. Dorsopathy. Thermography.

\section{RESUMO}

As dorsopatias são causas comuns de diminuição de desempenho em cavalos atletas de várias modalidades e a sela inadequada ou mal ajustada pode levar ao aparecimento de lesões e dor lombar. O presente trabalho avaliou a pressão que os suadores dos dois modelos de sela mais comumente utilizados em cavalos Árabes de enduro exercem sobre a região toracolombar desses animais de modo a sugerir o uso do que fosse mais adequado. Foram utilizados seis cavalos da raça Árabe, machos castrados, com peso de $390 \pm 4,2$ e idade $8 \pm 2,1$ anos, condicionados para as provas enduro de velocidade livre e dois modelos de sela, a Inglesa e a Western. Os cavalos foram submetidos ao trabalho montado em pista de areia pelo mesmo cavaleiro, experiente, que pesou $76 \mathrm{~kg}$. Foi realizada a termografia antes e depois das sessões de exercício. Os dados obtidos foram analisados através de teste T pareado de Student a 5\% de significância. Houve diferença de temperatura média, após o exercício, entre as áreas de contato dos suadores direito e esquerdo da sela Inglesa e da sela Western, quando comparados, sendo que a sela Inglesa apresentou maiores temperaturas. Portanto, o modelo de sela Western, que possui suadores largos, embora não seja o modelo de preferência dos cavaleiros de enduro, mostrou-se mais adequado para o trabalho de cavalos Árabes.

Palavras-chave: Ergometria de sela. Cavalo de enduro. Dorsopatias. Termografia.

Correspondence to:

Renata Farinelli de Siqueira

Universidade Cruzeiro do Sul, Departamento de Medicina

Veterinária

Av. Dr. Ussiel Cirílo, 225, Vila Jacuí

CEP: 08060-070, São Paulo - SP, Brasil

e-mail: refarinelli@yahoo.com.br

Received: June 27, 2019

Approved: September 20, 2019
How to cite: Siqueira RF, Andrioli BM, Baumhak MJ. Evaluation of two models of saddles on the back of Arabian horses through thermography. Braz J Vet Res Anim Sci. 2019;56(4):e159435. https://doi.org/10.11606/issn.1678-4456.bjvras.2019.159435

\section{Introduction}

Any equestrian sport is directly linked to balance, as the rider's center of gravity must be aligned with the horse's center of gravity. For this to occur, the saddle must be balanced, with the 
rider maintaining good posture. Therefore, the most common cause of low back pain is saddle-induced pain from improper adjustment or improper positioning (De Cocq et al., 2009).

Except for lameness, one of the main causes of change in gait and performance of athletic horses is back pain. Performance impairment caused by lower back pain is common in many horse breeds and in various sports. The presentation, location and identification of the painful area make its etiological diagnosis a challenge (Harman \& Backs, 1992; Jeffcott et al., 1983; Jeffcott, 1978, 1985; Koch, 1980; Rooney, 1982) reports that this decrease in performance can reach $60 \%$ of animals with low back pain. The presentation, location and identification of the painful area make its etiological diagnosis a challenge.

Meschan et al. (2007), demonstrated that under poorly fitted saddles, the load (rider and saddle mass) is distributed over a smaller area, leading to pressure peaks compared to properly fitted saddles. The way that a rider distributes his weight on the saddle is an important aspect that determines whether a horse can easily and freely move under a rider.

In painful processes, thermography allows the mapping of possible injuries present in the thoracolumbar region. Two distinct thermal imaging patterns suggestive of injury can be found: hot and cold areas. The former is caused by local temperature rise due to inflammatory processes. Cold areas are caused by painful lesions that stimulate sympathetic nerve trunks that emerge from the intervertebral foramina and innervate joints as well as skin and musculature, causing vasoconstriction. Because thermography detects the thermal state of the examined region, it can be used to determine the clinical significance of the lesions found on physical examination (Boffi et al., 2006; Piercy \& Rivero, 2007; Turner, 1991). Other studies have found infrared thermography to be a valuable tool in non-invasive evaluation of saddle thermal pattern distribution (Arruda et al., 2011; Soroko et al., 2018). Soroko et al. (2019) evaluated 18 racehorses that were ridden by four riders with their own saddles and concluded that infrared thermography offered a non-invasive, rapid and simple method for assessing load on thermal pattern distribution in race saddles.

The present investigation was performed to evaluate the pressure that panels of two different saddle models most commonly used in Arabian endurance horses exerts on the thoracolumbar region of these animals, searching for the most appropriate one, based on thermography results.

\section{Material and Methods}

This study was conducted at Santa Gertrudis Farm, located in Leme - SP (Brazil), which has training horses for endurance rides. For this purpose, 6 Arabian horses, geldings, weighing $390 \pm 4.2$ and age $8 \pm 2.1$ years and conditioned for free-speed races were used.

Two saddle models were used, English and Western, weighing $7.87 \mathrm{~kg}$ and $7.56 \mathrm{~kg}$, on digital scales, respectively. The horses underwent sand-track work by the same experienced rider who weighed $76 \mathrm{~kg}$.

The anatomical linear measurements of the horses were obtained with the aid of a tape measure, according to Donofre et al. (2014): ML1: caudal cranial length from the scapulohumeral joint to the caudal portion of the gluteal muscle; ML2: length from the scapulohumeral joint to the vertical tangent from the spinous process of the fifth thoracic vertebra; ML3: distance from the axial tangent of the spinous process of the fifth thoracic vertebra to the fifth lumbar vertebra; ML4: distance from the vertical tangent of the fifth lumbar vertebra to the ventral inguinal margin and horizontal tangent of the inguinal margin to the caudal margin of the gluteus muscle. The purpose of these measurements was to determine the length of the horse and back and compare them to other breeds that use these saddle models.

In the stall where the thermography was performed, a digital thermo-hygrometer was fixed to obtain the ambient temperature and relative humidity, because in the evaluation of the images through the software these values were considered.

The horses were brushed half an hour before the examination and kept in a stall protected from wind and solar radiation. The thermography of the saddle to be used and the thoracolumbar region of the animals was performed before exercise.

The horses were worked mounted according to the established protocol, which consisted of 5 min of walk (warm-up), 10 min trotting, 3 min cantering and 2 min of walk, and all movements were repeated on both sides. In all exercises, one person with a stopwatch was on the track marking the time that the horse should change pace or side. As soon as they returned to the stall, saddle thermography was performed, and the animal was placed in the stall for $30 \mathrm{~min}$ for acclimatization. Thermographic exam of the thoracolumbar region was repeated to determine the pressure points of the saddle panels on the back of the horse.

The images were obtained from a FLIR thermal imager model T450 (FLIR Thermal Infrared Camera Systems, Inc., Danderyd, Sweden), placed 1.5 meters away from the area, with an emissivity (e) between 0.99 and 1.0 and a temperature range between $14^{\circ} \mathrm{C}$ and $37^{\circ} \mathrm{C}$. The analysis was performed quantitatively through the FLIR tools program, which allows the delimitation of areas in the photo 
obtained, temperature capture of the entire enclosed area as well as the hottest and coldest points. The temperature observed on both sides of the animal's back before and after the exercise and the pressure points exerted by the saddle panels (hottest points) were compared. The images obtained from the saddle thermography were also compared to the images obtained from the horse thermography.

The data obtained were tested for normality through the Kolmogorov-Smirnv test and, subsequently, were analyzed by a paired Student $\mathrm{t}$-test at $5 \%$ significance, performed in the Minitab ${ }^{\circledast} 17$ program.

This study was approved by CEUA of the University of Guarulhos under protocol No. 30/16, on March 20, 2017.

\section{Results and Discussion}

The starting point for this study was to obtain measurements of body proportions that could influence saddle coaptation, since the purebred Arabian breed does not yet have this standardization, but it is popularly known as a "short-backed" breed. Donofre et al. (2014) conducted a morphometric study of Quarter Horses trained for drum testing based on 12 linear body measurements. The linear measure 3 (ML3) comprises the withers and back zootechnical parts, i.e., the bearing positions of both saddles. The average ML3 of Arabian horses was $66.33 \mathrm{~cm}( \pm 2.29)$, like that found in Quarter Horses evaluated by Donofre et al. (2014), which was $61.64 \mathrm{~cm}$. This leads us to think it is not the size of the back that limits the use of the saddle with straight pannels in this breed, but a cultural issue.

Because dynamic examination of the saddle in the horse is difficult, analysis of the thoraco-lumbar thermograph images is useful for detecting anomalous saddle pressure points. Thermography measures the superficial heat of the skin. However, this heat reflects metabolic modifications of the muscle that the saddle supported, such as greater or lesser blood flow (Meschan et al., 2007). After the proposed exercise was completed, thermography of the thoracolumbar region was performed in all animals and the results are presented in Table 1.

There was no statistical difference between the temperatures obtained from the thoracolumbar region of the horses, comparing the two saddle models. However, when analyzing the temperature averages of the thoracolumbar region after exercise, we observed that those who worked with the Western saddle presented lower temperature.

Sweat marks produced by the horse can also help in the analysis of the saddle pressures. For example, Figure 1 shows an area at the withers that did not sweat, demonstrating too much pressure on that area that prevented sweating. Figure 2 shows an area of homogeneous sweat on the back, which means that the saddle pressure was perfectly distributed.

When the panel temperatures of both saddles were analyzed, a difference of more than $6^{\circ} \mathrm{C}$ was observed

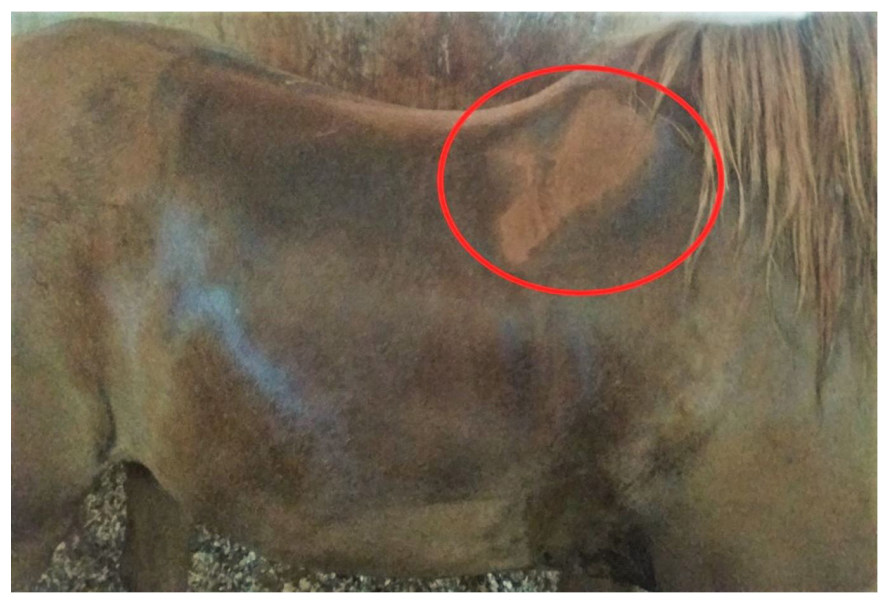

Figure 1 - Sweaty horse after exercise; however, showing a lack of sweat mark in the withers area (inside the red circle).

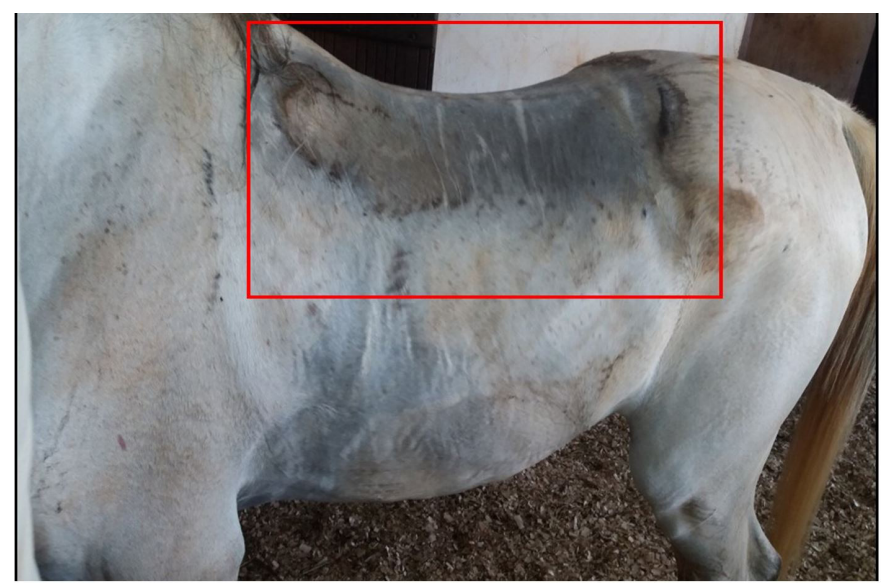

Figure 2 - Sweaty horse after being exercised with the Western saddle; however, showing a homogeneous sweat mark (within the red square).

Table 1 - Mean, standard deviation and the estimated temperature difference $\left({ }^{\circ} \mathrm{C}\right)$ obtained from the thoracolumbar region of horses after being worked with English and Western saddles

\begin{tabular}{|c|c|c|c|c|}
\hline & $\begin{array}{c}\text { English Saddle Left } \\
\text { Pannel }\end{array}$ & $\begin{array}{c}\text { Western saddle Left } \\
\text { Pannel }\end{array}$ & $\begin{array}{c}\text { English Saddle Right } \\
\text { Pannel }\end{array}$ & $\begin{array}{c}\text { Western saddle Right } \\
\text { Pannel }\end{array}$ \\
\hline Average & $32.63( \pm 0.29)$ & $32.52( \pm 0.61)$ & $32.73( \pm 0.26)$ & $32.52( \pm 0.66)$ \\
\hline$P$ & \multicolumn{2}{|c|}{0.868} & \multicolumn{2}{|c|}{0.770} \\
\hline Estimated difference & \multicolumn{2}{|c|}{0.117} & \multicolumn{2}{|c|}{0.217} \\
\hline
\end{tabular}


between the English saddle and the Western saddle, as shown in Table 2 and Figure 3.

A difference in temperature between the saddle panels above $2^{\circ} \mathrm{C}$ suggests incorrect saddle fit. Previous study conducted by Soroko et al. (2013) indicated temperature differences of $1^{\circ} \mathrm{C}$ in the diagnosis of pathological conditions.

There was a difference in mean temperature after exercise between the contact areas of the right and left panels of the compared English and Western saddles. The panels are the parts in direct contact with the horse's back exerting pressure, being important elements to optimize saddle adjustment, horse and rider comfort, and pain management in the injured horse, as shown in Figure 2. Although the proportions of the linear measurements are similar between the horses analyzed in the present study, the conformation of the back and chest varies, as does the course. According to Greve \& Dyson (2014) and Greve et al. (2015), the saddle should fit the horse, both at rest and in exercise, because during movement, the saddle's support points change, so the saddles must be individual.

A difficulty encountered by the veterinarian is to convince the rider that the saddle should be comfortable for him, but mainly for the horse. Another point, reported by
Arruda et al. (2011) is the saddle placement on the horse, which is almost always shifted forward, especially when using English saddles.

Martin et al. (2017) evaluated the effect that a prototype saddle with wide panels and a standard saddle exert on the horse's back and biomechanics through pressure sensors, 2D kinematics and stirrup force sensors. They concluded that the pressure exerted by the prototype panels was more homogeneous, improving the flexion and extension movements of the back of the horses. In the horse, many factors that can potentially influence the change of the trunk dimensions during exercise and, one of them is the conformation. Correct adjustment of the saddle is fundamental for the optimal functioning of the thoracolumbar region. The poorly adjusted saddle prevents biomechanical function and muscle development, leading to muscle pain and atrophy (Greve et al., 2015).

The Western model saddle was developed to work with cattle, where the rider stays seated all the time. The endurance race, although it takes many hours, is also carried out in diversified terrain and, therefore, requires that the rider is free on the saddle, sitting at the step and gallop, but managing to raise the trot. This freedom is

Table 2 - Mean and standard deviation $\left( \pm\right.$ ) of the temperatures in ${ }^{\circ} \mathrm{C}$ obtained after exercise, of the panels of the English and Western saddles, and the estimated difference

\begin{tabular}{|c|c|c|c|c|}
\hline & $\begin{array}{c}\text { English Saddle Left } \\
\text { Pannel }\end{array}$ & $\begin{array}{c}\text { Western saddle Left } \\
\text { Pannel }\end{array}$ & $\begin{array}{c}\text { English Saddle Right } \\
\text { Pannel }\end{array}$ & $\begin{array}{c}\text { Western saddle Right } \\
\text { Pannel }\end{array}$ \\
\hline Average & $31.46( \pm 0.37)$ & $25.03( \pm 0.47)$ & $31.78( \pm 0.46)$ & $25.23( \pm 0.40)$ \\
\hline$P$ & \multicolumn{2}{|c|}{0.000} & \multicolumn{2}{|c|}{0.000} \\
\hline Estimated difference & \multicolumn{2}{|c|}{6.43} & \multicolumn{2}{|c|}{6.55} \\
\hline
\end{tabular}

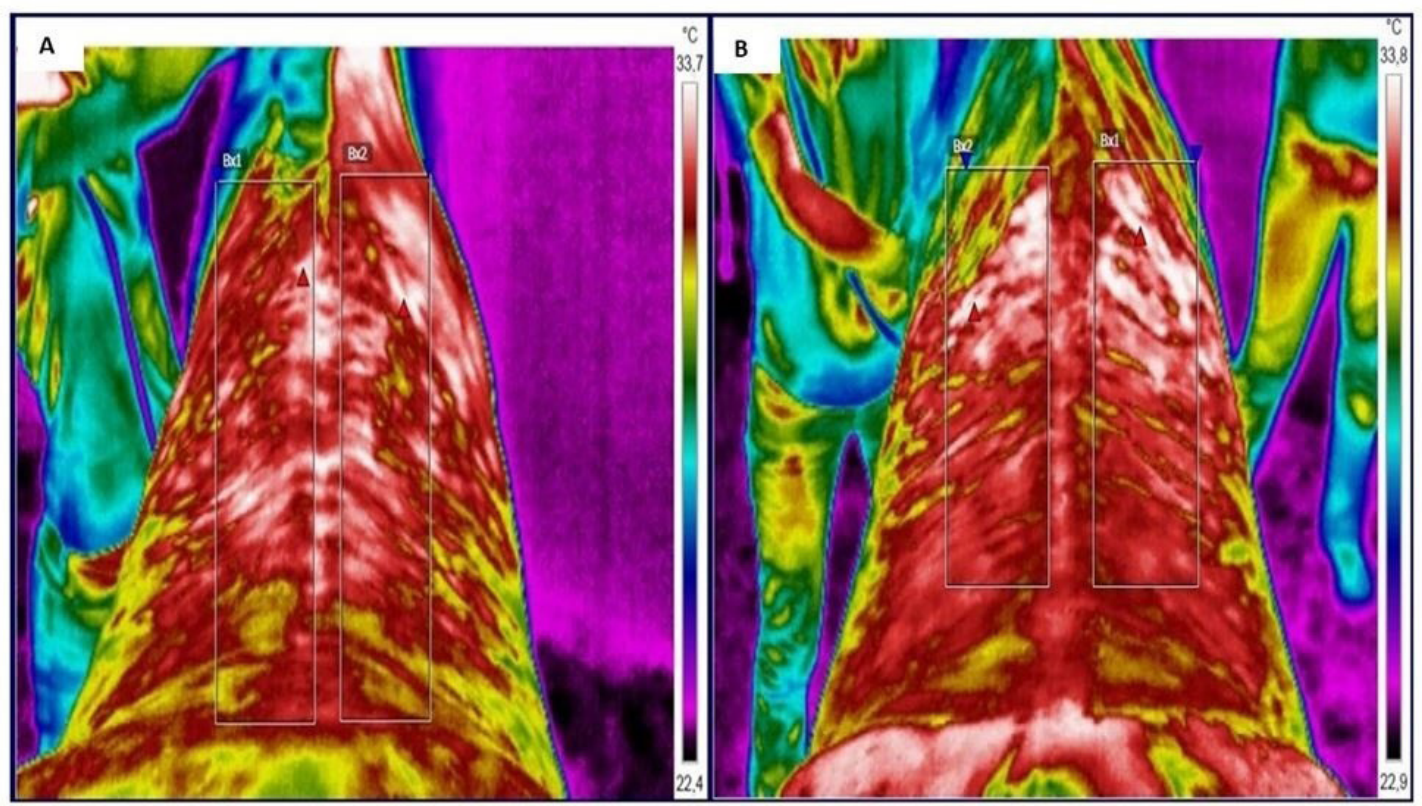

Figure 3 - Examples of obtained termographic images of the same horse after being worked with the English saddle (A) and Western saddle (B). 
conferred by the center of gravity, which in the Western saddle is shifted back. Perhaps this is another reason, besides aesthetic and cultural, that the endurance riders prefer the English saddle.

\section{Conclusion}

Although the Western style saddle is not the preference of endurance riders, it was more suitable in this study for the backs of Arabian horses, as the saddles have wider panels and better support the horses' musculature, based on thermography results.

\section{References}

Arruda TZ, Brass KE, De La Corte FD. Thermographic assessment of saddles used on jumping horses. J Equine Vet Sci. 2011;3(11):625-9. http://dx.doi.org/10.1016/j. jevs.2011.05.011.

Boffi FM, Cittar JS, Balskus G. Diseases that afectan el rendimiento deportivo. In: Boffi FM. Physiology del ejercicio en horses. Vol. 18. Buenos Aires: Inter-doctor; 2006. p. 255-66.

De Cocq P, Clayton HM, Terada K, Muller M, van Leeuwen JL. Usability of the normal force distribution measurements to evaluate asymmetrical loading of the back of the horse and rider different positions on a horse standing. Vet J. 2009;181:266-73. http://dx.doi.org/10.1016/j.tvjl.2008.03.002. PMid:18502669.

Donofre AC, Puoli JNP Fo, Ferreira IEP, Mota MDS, Chiquitelli M No. Balance of race horses Quarter Horse participants of the three reel mode through body proportions. Rural Science. 2014;44(2):327-32. http://dx.doi.org/10.1590/ S0103-84782014000200021.

Greve L, Dyson S. The interrelationship of lameness, saddle slip and back shape in the general sports horse population. Equine Vet J. 2014;46(6):687-94. http://dx.doi.org/10.1111/ evj.12222. PMid:24372949.

Greve L, Murray R, Dyson S. Subjective analysis of exerciseinduced changes in back dimensions of the horse: the influence of saddle-fit, rider skill and work quality. Vet J. 2015;206(1):39-46. http://dx.doi.org/10.1016/j.tvjl.2015.06.009. PMid:26238979.

Harman C, Backs J. Performance and acupuncture. In: Proceedings of the Annual Convention of the American

\section{Conflict of Interest}

The authors state that they have no conflicts of interest to declare.

\section{Ethics Statement}

This study was approved by CEUA of the University of Guarulhos under protocol No. 30/16, on March 20, 2017.

\section{Acknowledgements}

We would like to thank the whole team of Haras Santa Gertrudes, Leme, S.P., Brazil.

Association of Equine Practioners; 1992. Orlando. Orlando: AAEP; 1992. v. 32, p. 339-48.

Jeffcott LB, Dalin G, Drevemo S, Fredricson I, Bergqvist KBA. Induction of back pain in trotting horses and its effect on performance. Svensk Veterinärtidning. 1983:35, suppl. 3:110-13.

Jeffcott LB. Disorders of the equine thoracolumbar spine a review. Journal Equine Medicine Surgery. 1978;2:9-19.

Jeffcott LB. The examination of a horse with a potential back problem. In: Proceedings of the Annual Convention of the American Association of Equine Practioners; 1985; Ontario. Ontario: AAEP; 1985. v. 31, p. 271-83.

Koch DB. Differential diagnosis and management of back pain in the horse. California Veterinarian. 1980;34(6):28-31.

Martin P, Cheze L, Pourcelot P, Desquilbet L, Duray L, Chateau $\mathrm{H}$. Effects of large saddle panels on the biomechanics of the equine back during rising trot: preliminary results. J Equine Vet Sci. 2017;48:15-22. http://dx.doi.org/10.1016/j. jevs.2016.08.006.

Meschan MS, Peham C, Schobesberger H, Licka TF. The influence of the width of the saddle tree and the forces on the pressure distribution under the saddle. Vet J. 2007;173(3):578-84. http://dx.doi.org/10.1016/j. tvjl.2006.02.005. PMid:16632390.

Piercy RJ, Rivero JLL. Muscle disorders of equine athletes In: Hinchcliff KW, Kaneps AJ, Geor RJ. Equine medicine and surgery. Edinburgh: Saunders; 2007. Chapter 6; p. 77-110. 
Rooney JR. The horse's back: biomechanics of lameness. Vet. Clinics of North America: Equine Practice. 1982;4(2):17-27.

Soroko M, Cwynar P, Howell K, Yarnell K, Dudek K, Zaborski D. Assessment of saddle fit in racehorses using infrared Thermography (IRT). J Equine Vet Sci. 2018;63:304. http://dx.doi.org/10.1016/j.jevs.2018.01.006.

Soroko M, Henklewski R, Filipowski H. The effectiveness of thermographic analysis in equine orthopedics. J. Equine Vet Sci. 2013;33:760-62.

Soroko M, Zaborski D, Dudek K, Yarnell K, Górniak W, Vardasca R. Evaluation of thermal pattern distributions in racehorse saddles using infrared thermography. PLoS One. 2019;14(08):1-16. http://dx.doi.org/10.1371/journal. pone.0221622. PMid:31449556.

Turner TA. Thermography of an aid to the clinical lameness evaluation. Vet Clin North Am Equine Pract. 1991;7(2):31138. PMid:1933566.

Financial Support: None.

Authors Contributions: Renata Farinelli de Siqueira, Beatriz Moreira Andrioli and Marina Juliani Baumhak: thermography images and analysis. Renata Farinelli de Siqueira: writing. 